
Satellite Radiances on Data Assimilation.

By 
This study incorporates time-varying aerosols into satellite radiance calculations within the Global Data Assimilation System (GDAS) to investigate its impact on African easterly waves (AEWs) and their environment. Comparison of analysis fields from the aerosol-aware experiment and an aerosol-blind control during August 2017 showed that the aerosol-affected radiances accelerated the African easterly jet and West African monsoon flow; warmed the Saharan boundary layer; and modified the AEW vorticity structure, with increases in the northern circulation and decreases in the southern circulation. Analysis fields from each experiment were used in the Global Forecast System (GFS) to examine differences in forecasting two AEW cases that developed hurricanes over the Atlantic, but were structurally different over North Africa. The aerosol-aware experiment reduced errors in forecasting the AEW case whose northern circulation interacted with a large-scale Saharan dust plume; neutral improvement was found for the other AEW, which did not contain a northern circulation nor interacted with a dust plume. radiative effects that operate on AEWs and their environment. That is, the aerosol-affected radiances produce corrections to the brightness temperatures that modify the analysis fields like dust aerosols that are radiatively coupled to the atmospheric variables in the forecast model. We show qualitatively that dust radiative effects are captured by the aerosol-affected radiances for the AEW case that interacted with a dust plume, which served to improve forecasts of the wave downstream. 
Despite contributing less than $1 \%$ of the total mass to the atmosphere, aerosols can have a

61 profound impact on weather and climate. This is especially the case in aerosol-rich regions, such

62 as North Africa, which is home to the largest loadings for mineral dust aerosols in the world. On

63 average, approximately 1000 Teragrams of dust are emitted from the Saharan Desert each year

64 (Huneeus et al. 2011). The emissions are driven by enhanced surface winds over extremely dry and erodible regions (Knippertz and Todd 2012). Once emitted, the dust mixes within the deep Saharan boundary layer (up to $500 \mathrm{hPa}$ ) and can form plumes that span thousands of kilometers. African easterly jet (AEJ) and African easterly waves (AEWs). The AEJ is a mid-tropospheric jet $(\sim 650 \mathrm{hPa})$ whose axis is centered on the southern edge of the Saharan Desert $\left(\sim 15^{\circ} \mathrm{N}\right)$, while AEWs are synoptic-scale waves that develop along the AEJ. The AEWs can have two cyclonic circulations, which reside on either side of the AEJ axis. The circulation south of the AEJ peaks at $\sim 650 \mathrm{hPa}$ and is frequently coupled to moist convection, while the northern circulation peaks at $\sim 850 \mathrm{hPa}$, is dry, and can be immersed in Saharan dust. Over the East Atlantic, the two circulation centers often merge into a single circulation, which can produce a favorable environment for tropical cyclogenesis (Ross and Krishnamurti 2007). Meanwhile the dust moves westward over the Atlantic within the Saharan air layer (SAL), which is an elevated layer of dry air that originates from the Saharan boundary layer. The dust-laden SAL can infiltrate the AEW's oceanic circulation, which suppresses convection and thus tropical cyclone development (Dunion and Velden 2004; Reale et al. 2009; Braun et al. 2016; Brammer et al. 2018). 
can influence AEWs through two distinct pathways (Bercos-Hickey et al. 2017). The first is through the average (in time or space) dust fields, which modify the ambient temperature and wind fields (i.e., the AEJ) that in turn affects the AEW structure and development (Jones et al 2004; Wilcox et al. 2010; Jury and Santiago 2010). The second is through the formation of large-scale episodic dust plumes, which when correlated with the wind and temperature of the wave can directly affect several AEW properties, including its growth rates, phase speeds, energetics, and spatial structures (Grogan et al. 2016, 2017, 2019; Nathan et al. 2017).

To incorporate the above-mentioned dust radiative effects into a numerical weather prediction (NWP) system, it is important to represent the realistic nature of the aerosols. Studies have done this by including prognostic aerosol fields in the forecast model, which has shown to improve forecast skill in dust-affect regions, such as over North Africa and the East Atlantic (e.g., Perez et al. 2006; Mulcahey et al. 2014; Reale et al. 2014). But simulating prognostic aerosols is often not feasible in an operational setting due to computational costs. Thus, most operational NWP systems use prescribed aerosol climatologies, such as the NCEP operational Global Forecast System (GFS; Hou et al. 2002) and the ECMWF integrated forecast system (IFS; Bozzo et al. 2017). Consequently, the NWP system sacrifices the ability to represent the episodic aerosol signals.

Few other studies have incorporated aerosols into the NWP system through the data assimilation system. For example, Kim et al. (2018) included 3-hourly aerosol fields from the Goddard Chemistry Aerosol Radiation and Transport (GOCART) model into the radiance calculations within the Goddard Earth Observing System (GEOS)-atmospheric data assimilation system (ADAS). They showed that when aerosols were considered, the fit to observations from 
brightness temperatures (BT), which has been documented in previous studies (e.g., Sokolik 2002). As a result, Kim et al. (2018) showed that the aerosol cooling on the BT led to heating of the analyzed surface temperature in the Tropical Atlantic.

Similar to Kim et al. (2018), Wei et al. $(2020,2021)$ included aerosols from the NOAA Environmental Modeling System (NEMS) GFS Aerosol Component (NGAC) into NCEP's global

110 data assimilation system (GDAS). As a result, they found warmer analyzed sea surface

111 temperatures in the Atlantic and warmer low-level analyzed air temperatures over Africa and the

112 transatlantic region. Wei et al. (2020) also showed that the aerosols improved the forecasting of

113 vector winds and geopotential heights at multiple levels in the tropical region. Most operational

114 NWP systems, however, ignore this process despite its relatively low computational cost.

115 Motivated by the results in Kim et. al. (2018) and Wei et al. (2020, 2021) and the impacts

116 of dust radiative effects on AEWs, this study examines how aerosols in the satellite radiance

117 calculations of the data assimilation system can affect analyses and forecasts of the atmosphere

118 over North Africa and the East Atlantic. We focus on two AEWs during August 2017 that are

119 structurally different over North Africa but later developed hurricanes over the Atlantic. In Section

1202 , we describe the model experiments and the methods used to track the AEWs. Section 3 presents

121 the analysis differences and forecast performances from each experiment. Section 4 discusses the

122 results of the aerosol-aware experiment and its relationship to dust radiative effects on AEW within

123 the analysis fields. Section 5 provides concluding remarks.

\section{2. Experiments and Methods}

\subsection{Model Experiments}

126 To investigate the impact of incorporating aerosols into the assimilation of satellite 127 radiances, this study employs version 14 (v14) of NCEP's GFS forecast model and the 
corresponding GDAS. Briefly, the GFS v14 is a global spectral model that accounts for aerosol direct radiative effects using prescribed monthly aerosol climatologies from the Optical Properties

130 of Atmospheric Composition (OPAC) software package (Hess et al. 1998). Meanwhile, the GDAS

131 is a Gridpoint Statistical Interpolation (GSI) based four-dimensional ensemble-variational 132 (4DEnVar) assimilation system that excludes any explicit treatment of aerosols. For our study, the 133 NWP system is run at coarser resolution than NCEP's operational settings: we use T670 ( $\sim 30 \mathrm{~km})$ resolution for the GFS forecast model and 80 ensemble members running at T254 $(\sim 80 \mathrm{~km})$ resolution for GDAS.

The schematic in Fig. 1 illustrates the workflow of each experiment in this study. Two experiments were conducted, spanning from July 25th - August 28th, 2017. The first experiment is an aerosol blind run (CTL), where the aerosol effects on radiance are not considered in GDAS (as is by default). The second experiment is an aerosol-aware run (AER), which incorporates timevarying aerosol information into the radiance calculations within GDAS. Both cases are fullycycled runs, meaning that each 6-hour analysis is constructed using forecasts from the prior cycle of the respective experiment.

To enable the aerosol-aware option in AER, mixing ratios of dust, sea-salt, sulfate, organic 144 carbon and black carbon aerosols from the NGAC, v2 model (Wang et al. 2018) are ingested into 145 GDAS and passed to the Community Radiative Transfer Model (CRTM, v2.2.4), which is the 146 radiance observation operator in GSI. Briefly, the CRTM contains a fast-forward radiative model, 147 which generates simulated BTs for the observations in the same space-time domain, and also 148 contains Tangent-Linear, Adjoint, and K-Matrix models, which together compute the radiance 149 sensitivities with respect to the state variables (Han et al. 2006). More details on the 

methodology as this study.

In addition to the fully cycled analyses, we also produced 34 consecutive GFS forecasts for CTL and AER during the period of interest (July 25th-August $28^{\text {th }}$ ). Each forecast was initialized at $00 \mathrm{Z}$ of the respective analysis and ran for 120 hours. Despite having differences in the GDAS configuration, both experiments use the same forecast model (i.e., the GFS v14), which is radiatively coupled to prescribed OPAC aerosol climatologies. This means that differences between the two sets of forecasts arise solely by the initial conditions via the incorporation of aerosols in the GDAS radiance calculations, rather than adjustments to the physics within the GFS forecast model.

\subsection{Wave tracking} tracking algorithm similar to that in Brammer and Thorncroft (2015). Briefly, the tracking algorithm involves analyzing mass-weighted centers of vorticity at multiple levels (i.e., curvature vorticity at 850,700 , and $500 \mathrm{hPa}$; relative vorticity at 850 and $700 \mathrm{hPa}$ ). The wave center is then determined from a weighted average of the centers within a specified radius $(500 \mathrm{~km})$. For each experiment, the wave centers were extracted using the 6-hourly analysis fields, which identified several systems that traversed Africa and the east Atlantic. This included waves that later developed hurricanes, which we focus on in this study given their long lifetimes and downstream implications.

For our time period of interest, two hurricanes developed from AEWs: Gert (2017) and Harvey (2017). Figure 2 shows the objective track locations for the AEWs that developed hurricane Gert and Harvey in CTL (blue) and AER (red) over North Africa and the East Atlantic. 
173 For Gert (Fig. 2a), the tracks show that the storm originates over Northeast Africa, at $5-10^{\circ} \mathrm{N}$, 174 and moves northwestward over North Africa and the East Atlantic. In contrast, Harvey (Fig. 2b) originates from two circulations over North Africa, at $25-29^{\circ} \mathrm{N}$ and $8-12^{\circ} \mathrm{N}$, which merge into one circulation near the coast that moves west/southwest over the East Atlantic. Both waves developed hurricanes while over the western portion of the Atlantic Ocean. positions during their evolution over North Africa and the East Atlantic. After the initial development, the track locations among the two cases are less than $250 \mathrm{~km}$. Given the wavelength of the AEWs span 2000 - $5000 \mathrm{~km}$ (Burpee 1974), the aerosol-aware assimilation does not appear to have a significant influence on the wave tracks. Therefore, we use track locations from CTL to investigate the storm structures in the analyses and forecasts for both cases in the next section.

184 3. Results

\subsection{Analysis Differences: Time-average fields}

Before investigating the AEW cases shown in Fig. 2, we first examine the aerosol impacts on the time-averaged fields that the waves propagate through. Figure 3 shows cross-sections of the zonal wind and temperature for CTL (contours) and the AER - CTL difference (colors) averaged over August 2017.

190 Consider first the CTL run. The experiment captures the main summertime circulation 191 features over the region, including the well-defined AEJ (Fig. 3a: $15^{\circ} \mathrm{N}, 600 \mathrm{hPa}$ ) that extends 192 across North Africa and the East Atlantic (Fig. 3b: $20^{\circ} \mathrm{W}-25^{\circ} \mathrm{E}, 10-15^{\circ} \mathrm{N}$ ) and the low-level 193 westerlies associated with the West African Monsoon (WAM) flow (Fig. 3a: $1000-800 \mathrm{hPa}$ ). The

194 CTL experiment also accurately positions the warmest air temperatures near the surface over the 
Saharan Desert, which consequently sets up a strong meridional temperature gradient in the Sahel that drives the AEJ (Fig. $3 \mathrm{c}: 10-20^{\circ} \mathrm{N}, 1000-650 \mathrm{hPa}$; Fig. $3 \mathrm{~d}$ : $15^{\circ} \mathrm{W}-20^{\circ} \mathrm{E}, 10-15^{\circ} \mathrm{N}$ ). the time-averaged analysis fields. For the zonal wind, the differences indicate that AER accelerates the AEJ core by $\sim 0.5 \mathrm{~m} / \mathrm{s}$ across North Africa and the Eastern Atlantic (blues in Fig. 3a: $14-16^{\circ} \mathrm{N}$, $700-600 \mathrm{hPa}$, and Fig. $3 \mathrm{~b}: 20^{\circ} \mathrm{E}-30^{\circ} \mathrm{W}, 10-15^{\circ} \mathrm{N}$ ), accelerates the WAM flow by $\sim 0.5 \mathrm{~m} / \mathrm{s}$ (reds in Fig. $3 \mathrm{a}: 12-22^{\circ} \mathrm{N}, 1000-800 \mathrm{hPa}$ ), and accelerates the easterly flow by $\sim 0-2-0.5 \mathrm{~m} / \mathrm{s}$ south of the AEJ axis (blues in Fig. 3a: $12-22^{\circ} \mathrm{N}, 1000-600 \mathrm{hPa}$ ). The accelerated flows infer a structural change in the AEJ, including intensifying the low-level vertical shear north of the AEJ core $\left(15-22^{\circ} \mathrm{N}, 900-700 \mathrm{hPa}\right)$ and weakening the mid-level horizontal shear south of the AEJ axis $\left(8-12^{\circ} \mathrm{N}, 800-600 \mathrm{hPa}\right)$.

For AER - CTL difference in ambient temperature, the aerosol impacts warm the Sahara and Sahel in the boundary layer (reds in Fig. $3 \mathrm{c}: 10-30^{\circ} \mathrm{N}, 1000-500 \mathrm{hPa}$ ) and cool the marine boundary layer below the SAL (blues in Fig. $3 \mathrm{~d}: 15-25^{\circ} \mathrm{W}, 15-30^{\circ} \mathrm{N}$ ). Over the Sahara, the heating peaks at $800 \mathrm{hPa}$, which in turn, infers a region of reduced static stability below the peak heating $\left(15-25^{\circ} \mathrm{N}, 1000-800 \mathrm{hPa}\right)$. These temperature changes are qualitatively consistent with enhanced aerosol heating in the boundary layer over the continent and in the SAL offshore. The temperature changes also support the corresponding zonal wind changes via thermal wind. For example, the additional warming in the Saharan boundary layer will enhance the meridional temperature gradient in the Sahel $\left(10-20^{\circ} \mathrm{N}\right)$. This increases the vertical shear at low- and midlevels (1000-500 hPa), driving accelerations in the WAM below and AEJ above. 
218 averaged cross-sections of the relative vorticity amplitude modulus; this quantity is a proxy for

219 AEW activity but has limitations as it includes the cyclonic and anticyclonic vorticity from all 220 scales in its computation.

Figure 4 shows the vorticity modulus for CTL (contours), which picks up the two AEW tracks over the interior of North Africa. The wave structures peak at levels consistent with AEWs examined in previous studies (southern: $8-13^{\circ} \mathrm{N}, 800-600$; northern: $18-22^{\circ} \mathrm{N}, 950-700 \mathrm{hPa}$ ). Moreover, the AER - CTL differences (colors) show that AER modified the two tracks by increasing vorticity by $\sim 15 \%$ in the northern circulation ( $800-1000 \mathrm{hPa}$ ) and decreasing it by $\sim 10 \%$ in the southern circulation $(700-900 \mathrm{hPa})$. To determine if these changes are associated with the AEWs, we next investigate our cases identified in section 2.

Figures 5-8 shows the horizontal and vertical structures of the AEW cases as they transverse across North Africa. The horizontal structures in Figs. 5 and 7 respectively show the $700 \mathrm{hPa}$ and $850 \mathrm{hPa}$ CTL streamlines (contours) and the AER - CTL differences in the cyclonic vorticity at the level of the streamlines (colors); the wave centers are denoted by X's. Figures 6 and 8 show the corresponding vertical structure of the vorticity, circular averaged around the wave centers (radius $500 \mathrm{~km}$ ). Because the AEW that developed Harvey has two circulations, Fig. 8 shows the vertical structures of the northern and southern wave centers for Aug $9^{\text {th }}-10^{\text {th }}$, which are the times when the AEW amplitudes were largest over Africa

For the AEW that developed Gert, Fig. 5 shows the wave structure is confined south of the AEJ (i.e., south of $15^{\circ} \mathrm{N}$ ) as it crosses North Africa. This region is largely aerosol-free during this time of year, but the aerosol-aware assimilation still clearly affects the evolution of the wave structure (colors surrounding the X's). For example, on Aug $2^{\text {nd }}$ and $3^{\text {rd }}$, Figs. $5 \mathrm{~b}$ and $5 \mathrm{c}$ show the 
241 AER run decreases the cyclonic vorticity (blues surrounding the X's). Looking at the average vertical structure of the AEW vorticity, Fig. 6 shows that amplitudes for CTL (blue) are as much as $20 \%$ larger than AER (red) from $600-800 \mathrm{hPa}$. Thus, the reduced vorticity in AER for this case is consistent with the time-averaged vorticity moduli shown for the AEW southern track (Fig. 4).

For the AEW that developed Harvey, Fig. 7 shows that the wave has two prominent cyclonic circulations and a broad structure that covers a large portion of North Africa. The AER run produces changes to both circulation centers, which include increasing the vorticity around the northern circulation structure (reds at $18^{\circ} \mathrm{N}$ ) and decreasing the southern circulation (blues at $\left.14^{\circ} \mathrm{N}\right)$. During August $9^{\text {th }}$ and $10^{\text {th }}$, which are times when the AEW amplitudes are largest, Fig. 8 shows that the vorticity at $600-850 \mathrm{hPa}$ is, on average, $\sim 20-35 \%$ larger for the northern circulation (Figs. $8 \mathrm{a}$ and $8 \mathrm{c}$ ), and $\sim 20-35 \%$ smaller for the southern circulation (Figs. $8 \mathrm{~b}$ and $8 \mathrm{~d}$ ). Therefore, the changes to the vorticity for this case are also consistent with those from the time-averaged vorticity moduli shown in Fig. 4. Moreover, the aerosol impacts on this AEW are more intense than for the AEW that developed Gert.

\subsection{Forecast Differences: AEW cases}

To examine the impact of the aerosol-aware assimilation on the forecasts for our AEW cases, we compared the Root-Mean-Square-Error (RMSE) in vorticity for CTL and AER; the forecasts were verified against their respective analysis. Table 1 shows the RMSE relative differences between AER and CTL for the 1000 - $500 \mathrm{hPa}$ vorticity following the AEWs that developed Gert and Harvey. To compute the RMSE following the AEW at each forecast time, we used the CTL wave locations shown in Section 2. For Gert, a $10^{\circ}$ latitude by $10^{\circ}$ longitude window 
$2645-25^{\circ} \mathrm{N}$ and a $15^{\circ}$ longitude range that was centered on the two circulations; over the Atlantic

265 Ocean, a $10^{\circ}$ latitude by $10^{\circ}$ longitude window was centered on the merged circulation.

266 Table 1 shows the AER run produced neutral improvement in the forecasting of the AEW

267 that developed Gert, as evidenced by the mixture of red and green values in the RMSE relative

268 differences. Inspection of the forecasts show that both AER and CTL underestimated the

269 intensification of the AEW when initialized onshore, on July $31^{\text {st }}-$ Aug $2^{\text {nd }}$, and overestimated the

270 intensification when initialized offshore, on Aug $3^{\text {rd }}$. As a result, there were several instances

271 where the RMSE forecast differences did not produce statistically significant results (i.e., crossed

272 out values for Gert in Table 1).

273 In contrast to the AEW that developed Gert, Table 1 shows the AER run produced

274 statistically significant improvement in forecasting the AEW that developed Harvey. The largest

275 improvements were found on the forecasts initialized on August $10^{\text {th }}$ and $11^{\text {th }}$, with the forecast on

276 August $10^{\text {th }}$ showing reductions in RMSE on every forecast day (errors reduced by $\sim 15-49 \%$ ). For

277 the initialized times examined for Harvey (Aug $8^{\text {th }}-11^{\text {th }}$ ), both the analyzed amplitudes and AER

278 - CTL vorticity differences were larger than Gert while onshore (cf. Figs. 6 and 8). Inspection of

279 the forecasts revealed that the CTL run continued to suppress the storm downstream while the

280 AER run better maintained the intensity of the storm as the two circulations merged over the East

281 Atlantic and traveled downstream.

282 4. Discussion

283 In this section, we discuss the relationship between the analysis differences shown in 284 section 3.1 and 3.2 to the impacts of dust when aerosols are radiatively coupled to the forecast 285 model, as well as the implications of the analysis differences on the forecasting of our AEW cases shown in section 3.3 . 

the AER run accelerated the AEJ and WAM, and warmed the Saharan boundary layer. These changes, in turn, affect the structure of the wind shear and static stability that, in part, can explain the structural changes in the time-averaged vorticity amplitudes associated with the AEWs. This can be inferred from local wave energetics (Norquist et al. 1977; Grogan et al. 2019). For example, enhanced low-level vertical shear and reduced static stability setup below the AEJ core will increase local baroclinic energy conversions and thus vorticity in the north circulation. Additionally, reduced horizontal shear south of the AEJ axis will decrease local barotropic energy conversions in the southern circulation. Thus, the aerosol-aware assimilation modifies the existing dust radiative effects coupled to the forecast model (i.e., from the OPAC aerosol climatology) that operate on the analyzed AEJ, temperature, and AEW structures. that developed Gert, we found average values of aerosol optical depth (AOD) over the Sahara during the wave's passage over North Africa. In contrast, the AEW that developed Harvey interacted with a strong Saharan dust plume as it crossed North Africa. This can be seen in Figure 9, which shows a snapshot of the AOD (brown contours) surrounding the AEW northern

303 circulation center $\left(13.5^{\circ} \mathrm{W}, 20^{\circ} \mathrm{N}\right)$ on August 10 th, at $12: 00 \mathrm{Z}$. Figure 9 also shows observations

304 from the Infrared Atmospheric Sounding Interferometer (IASI) that were assimilated over the 305 region at the same time; the observations are AER - CTL differences in the BT at $12.95 \mu \mathrm{m}$ 306 (circles). Most of the differences are negative (blue circles) meaning that the BTs are cooler in the 307 AER run. Additionally, the cooling is largest surrounding the northern circulation (up to $9 \mathrm{~K}$ ), 308 where AODs are large (over 1.0). This produced warmer analyzed temperatures throughout the 

the results in Kim et al. (2018) and Wei et al. (2020).

312 remarkably similar to the dust signal that forms and interacts with dust-coupled AEWs examined

313 in Grogan and Thorncroft (2019). In their study, Grogan and Thorncroft (2019) found that the

314 correlation between the enhanced heating rate from the dust signal and warm temperature

315 anomalies from the wave generated available potential energy that previous idealized studies

316 showed can amplify the local wave structure (Grogan et al. 2016, 2019; Nathan et al. 2017). Given

317 the amplified vorticity shown in the northern circulation for our case (Fig. 8), this implies that the

318 aerosol-aware assimilation captures the dust radiative effects on the AEW associated with the

319 episodic dust plume in the analysis.

320 The aerosol-aware assimilation adjusting and augmenting the synoptic patterns of the

321 analyzed AEWs can have implications on the subsequent forecasting of the waves. In section 3.3,

322 the aerosol-affected radiances showed neutral changes to the forecast error in the $1000-500 \mathrm{hPa}$

323 averaged vorticity for the AEW that developed Gert, but dramatic reductions in the forecast error

324 for the AEW that developed Harvey. This marked improvement is likely associated with the

325 aerosol-aware assimilation capturing the realistic representation of the large-scale Saharan dust

326 plume, and its corresponding radiative effects on the AEW. Therefore, this implies that the

327 treatment of episodic aerosols within the assimilation of the NWP system can improve forecasting

328 the evolution of AEWs.

\section{5. Conclusions}

330 In this study, we examined how incorporating time-varying aerosols into the assimilation 331 of satellite radiances affected the analyses and forecasts using GFS v14 and the corresponding 
GDAS. In particular, we investigated the aerosol impacts of Saharan dust on AEWs and their environment over North Africa and the East Atlantic during August 2017. over North Africa and the East Atlantic. For example, the aerosols warmed the Saharan boundary layer, accelerated the AEJ and WAM, and modified the AEW vorticity structure, with amplitudes increasing within the northern circulation and decreasing in the southern circulation. These vorticity changes in the AEW were also shown in individual cases examined, which were structurally different over North Africa but later developed into hurricanes over the West Atlantic. The impact of the analysis differences on forecasting the individual AEW cases was also examined. For the AEW that developed Gert, RMSE differences showed that the aerosol-aware experiment produced neutral improvement to the vorticity field among the forecasts tracking the wave over North Africa and the Atlantic. In contrast, the aerosols improved the vorticity field in most forecasts for the AEW that developed Harvey; the largest reductions in RMSE occurred when analysis differences in the AEW structures were largest. captured dust radiative effects on the AEW structure that are associated with the time-varying

348 aerosols in the radiance observation operator (i.e., CRTM). For example, the assimilation modified

349 the existing dust radiative effects operating on the analyzed AEJ and temperature, which in turn 350 modified the analyzed AEW vorticity structure. Additionally, the formation of an episodic plume 351 within the northern circulation of the AEW that developed Harvey enhanced warming and vorticity 352 in the region, which is a similar response shown previously for AEWs (e.g., Grogan et al. 2016; 353 Grogan and Thorncroft 2019). Consequently, the analysis changes significantly improved the 

determining the timing and location of tropical cyclogenesis that originate from developing AEWs. Aerosol radiative effects can be incorporated into the NWP system through the assimilation system and the forecast model. Though fewer studies focus on the assimilation aspect, this study has demonstrated the importance of incorporating time-varying aerosols into the satellite radiance calculations to capture dust radiative effects on the analyzed AEWs and environment. More work, however, is needed to better understand how to optimize the aerosol-aware assimilation, such as adjusting the bias-correction and quality-control procedures. Moreover, future work should investigate how much complexity is needed to represent aerosol processes adequately and accurately, and thus effectively account for aerosol effects within the NWP system.

\section{Data availability}

Analyses and forecasts from the AER and CTL runs can be provided upon request to the first author of the paper.

\section{Author contributions}

DG and SL developed the ideas for the study. SW and SC conducted the numerical experiments. DG, CL, and SW analyzed and interpreted the results. DG prepared the paper. CL and SW reviewed the paper.

\section{Competing interests}

The authors declare that they have no conflicts of interest.

\section{Acknowledgements}

The work presented here is supported by NOAA NWS NGGPS R2O (Award number 
https://doi.org/10.5194/acp-2021-129

Preprint. Discussion started: 21 July 2021

(c) Author(s) 2021. CC BY 4.0 License.

(c) (1)

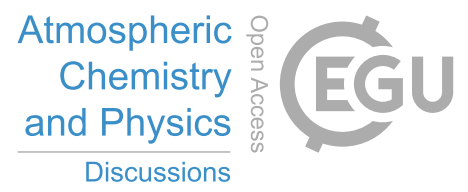

377 Collard, Jun Wang, Partha Bhattacharjee, Bert Katz, Xu Li), and NESDIS/STAR (Quanhua Liu,

378 Zhu Tong). The GDAS experiments were conducted at UW-Madison Space Science and

379 Engineering Center's Satellite Simulations and Data Assimilation Studies computer, or S4, cluster. 
Bercos-Hickey, E., Nathan, T.R., and Chen, S.-H.: Saharan dust and the African easterly jetAfrican easterly wave system: structure, location and energetics. Q. J. R. Meteorol. Soc., 143, 2797-2808, https://doi.org/10.1002/qj.3128, 2017.

Brammer, A., and Thorncroft, C.D.: Variability and evolution of African easterly wave structures and their relationship with tropical cyclogenesis over the eastern Atlantic. Mon. Wea. Rev. 143, 4975-4995, https://doi.org/10.1175/MWR-D-15-0106.1, 2015.

Brammer, A., Thorncroft, C.D., and J. Dunion: Observations and Predictability of a Nondeveloping Tropical Disturbance over the Eastern Atlantic. Mon. Wea. Rev., 146, 30793096, https://doi.org/10.1175/MWR-D-18-0065.1, 2018.

Bozzo, A., Remy, S., Benedetti, A., Fleming, J., Betchold, P., Rodwell, M.J., and Morcrette, J.-J.: Implementation of a CAMS-based aerosol climatology in the IFS. ECMWF Technical Memorandum, 801, Available at: https://www.ecmwf.int/en/elibrary/17771-radiationnumerical-weather-prediction (last access: 1 Feb 2021), 2017.

Braun, S.A., Newman, P.A., and Heymsfield, G.M.: NASA's Hurricane and Severe Storm Sentinel (HS3) Investigation. Bull. Amer. Meteor. Soc., 2016, 2085-2102, https://doi.org/10.1175/BAMS-D-15-00186.1, 2016.

Burpee, R.W.: Characteristics of North African Easterly Waves During the Summers of 1968 and 1969. J. Atmos. Sci., 31, 1556-1570, https://doi.org/10.1175/15200469(1974)031<1556:CONAEW>2.0.CO;2, 1974.

Dunion, J.P., and Velden, C.S.: The Impact of the Saharan Air Layer on Atlantic Tropical Cyclone Activity. Bull. Amer. Meteor. Soc., 2004, 353-366, https://doi.org/10.1175/BAMS-85-3353, 2004.

Grogan, D.F.P., Nathan, T.R., and Chen, S.-H.: Effect of Saharan dust on the linear dynamics of African easterly waves. J. Atmos. Sci. 73, 891-911, https://doi.org/10.1175/JAS-D-150143.1, 2016.

Grogan, D.F.P., Nathan, T.R., and Chen, S.-H.: Saharan dust and the nonlinear evolution of the African easterly jet-African easterly wave system. J. Atmos. Sci. 74, 24-47, https://doi.org/10.1175/JAS-D-16-0118.1, 2017.

Grogan, D.F.P. and Thorncroft, C.D.: The characteristics of African easterly waves coupled to Saharan mineral dust aerosols. Q. J. R. Meteorol. Soc. 2019, 1-17, https://doi.org/10.1002/qj.3483, 2019.

Grogan, D.F.P., Nathan, T.R., and Chen, S.-H.: Structural Changes in the African Easterly Jet and Its Role in Mediating the Effects of Saharan Dust on the Linear Dynamics of African Easterly Waves. J. Atmos. Sci. 76, 3359-3365, https://doi.org/10.1175/JAS-D-19-0104.1, 2019.

Han, Y., van Deist, P., Liu, Q., Weng, F., Yan, B., Treason, R., and Derber, J.: JCSDA community radiative transfer model (CRTM): Version 1. NOAA Technical Report NESDIS 122. Available at https://repository.library.noaa.gov/view/noaa/1157/noaa 1157 DS1.pdf (last access: 1 Feb 2021), 2006. 
Hess, M.P., Koepke, P., and Shult, I.: Optical properties of aerosol and clouds: The software package OPAC. Bull. Amer Meteor. Soc., 79, 831-844, https://doi.org/10.1175/15200477(1998)079<0831:OPOAAC $>2.0 . \mathrm{CO} ; 2,1998$.

Huneeus, N., Schulz, M., Balkanski, Y., Griesfeller, J., Prospero, M., Kinne, S., et al.: Global dust model intercomparison in AeroCom phase I. Atmos. Chem. Phys., 11, 7781-7816, https://doi.org/10.5194/acp-11-7781-2011, 2011.

Jones, C., Mahowald, N., and Luo, C.: Observational evidence of African desert dust intensification of easterly waves. Geophys. Res. Lett., 31, L17208, https://doi.org/10.1029/2004GL020107, 2004.

Jury, M.R. and Santiago, M.J.: Composite analysis of dust impacts on African easterly waves in the Moderate Resolution Imaging Spectrometer era. J. Geophys. Res., 115, D16213, https://doi.org/10.1029/2009JD013612, 2010.

Kiladis, G.N., Thorncroft, C.D., and Hall, N.M.J.: Three-Dimensional Structure and Dynamics of African Easterly Waves. Part I: observations. J. Atmos. Sci. 63, 2212-2230, https://doi.org/10.1175/JAS3741.1, 2006.

Kim, J., Akella, S., da Silva, A.M., Todling, R., and McCarty, W.: Preliminary evaluation of influence of aerosols on the simulation of brightness temperature in NASA's Goddard Earth Observing System Atmospheric Data Assimilation System. Technical Report Series on Global Modeling and Data Assimilation, 49. Available at https://ntrs.nasa.gov/api/citations/20180001946/downloads/20180001946.pdf (last access: 1 Feb 2021), 2018.

Knippertz, P., and Todd, M.: Mineral dust aerosols over the Sahara: Meteorological controls on emission and transport and implications for modeling. Rev. Geophgys., 50, RG1007, https://doi.org/10.1029/2011RG000362, 2012.

Hou, Y.-T., Moorhi, S., and Campana, K.: Parameterization of solar radiation transfer in the NCEP models. NCEP Office Note 441. Available at https://repository.library.noaa.gov/view/noaa/23085/noaa_23085 DS1.pdf (last access: 1 Feb 2021), 2002.

Mulcahey J.-P., Walters, D.N., Bellouin, N., and Milton, S.F.: Impacts of increasing the aerosol complexity in the Met Office global numerical weather prediction model. Atmos. Chem. Phys., 14, 4749-4778, https://doi.org/10.5194/acp-14-4749-2014, 2014.

Nathan T.R., Grogan, D.F.P., and Chen, S.-H.: Subcritical destabilization of African easterly waves by Saharan mineral dust. J. Atmos. Sci. 74, 1039-1055, https://doi.org/10.1175/JASD-16-0247.1, 2017.

Norquist D.C., Recker, E.R., and Reed, R.J.: The Energetics of African Wave Disturbances as observed During Phase III of GATE. Mon. Wea. Rev., 105, 334-342, https://doi.org/10.1175/1520-0493(1977)105<0334:TEOAWD>2.0.CO;2, 1977.

Carlos Pérez, C., Nickovic, S., Pejanovic, G., Baldasano, J.M., and Özsoy, E.: Interactive dustradiation modeling: A step to improve weather forecasts. J. Geophys. Res. Lett., 111, D16206, https://doi.org/10.1029/2005JD006717, 2006.

Reale, O., Lau, K.M., Kim, K.-Y., and Brin, E.: Atlantic Tropical Cyclogenetic Processes during 
SOP-3 NAMMA in the GEOS-5 Global Data Assimilation and Forecast System. J. Atmos. Sci., 66, 3563-3578, https://doi.org/10.1175/2009JAS3123.1, 2009.

Reale, O., Lau, K.M., da Silva, A.M., and Matsui, T.: Impact of assimilated and interactive aerosol on tropical cyclogenesis. Geophys https://doi.org/10.1002/2014GL059918, 2014.

Ross, R. S., and Krishnamurti, T.N.: Low-level African easterly wave activity and its relation to Atlantic tropical cyclogenesis in 2001. Mon. Wea. Rev., 135, 3950-3964, https://doi.org/10.1175/2007MWR1996.1, 2007.

Sokolik, I.: The spectral radiative signature of wind-blown mineral dust: Implications for remote sensing in the thermal IR region. Geophys. Res. Lett., 29, NO. 24, 2154, https://doi.org/10.1029/2002GL015910, 2002.

Wang, J., et al.: The implementation of NEMS GFS Aerosol Component (NGAC) Version 2.0 for global multispecies forecasting at NOAA/NCEP-Part 1: Model descriptions, Geosci. Model Dev., 11, 2315-2332, https://doi.org/10.5194/gmd-11-2315-2018, 2018.

Wei S.-W., Collard, A., Grumbine, R., Liu, Q., and Lu, C.-H.: Impacts of aerosols on meteorological assimilation: Aerosol impact on simulated brightness temperature and analysis fields. JCSDA Quarterly, 66, Spring 2020, https://doi.org/10.25923/4pt1-wx36, 2020.

Wei S.-W., Lu, C.-H., Liu, Q., Collard, A., Zhu, T., Grogan, D.F.P., Li, X., Wang, J., Grumbine R., and Bhattacharjee, P.: The impact of aerosols on satellite radiance data assimilation using NCEP global data assimilation system. Atmosphere, 12(4), 432, https://doi.org/10.3390/atmos12040432, 2021.

Wilcox E.M., Lau, K.M., and Kim, K.Y.: A northward shift of the North Atlantic Ocean Intertropical Convergence Zone in response to summertime Saharan dust outbreaks. Geophys. Res. Lett., 24, L04804, https://doi.org/10.1029/2009GL041774, 2010. 
https://doi.org/10.5194/acp-2021-129

Preprint. Discussion started: 21 July 2021

(c) Author(s) 2021. CC BY 4.0 License.
Atmospheric

Chemistry

and Physics

Discussions

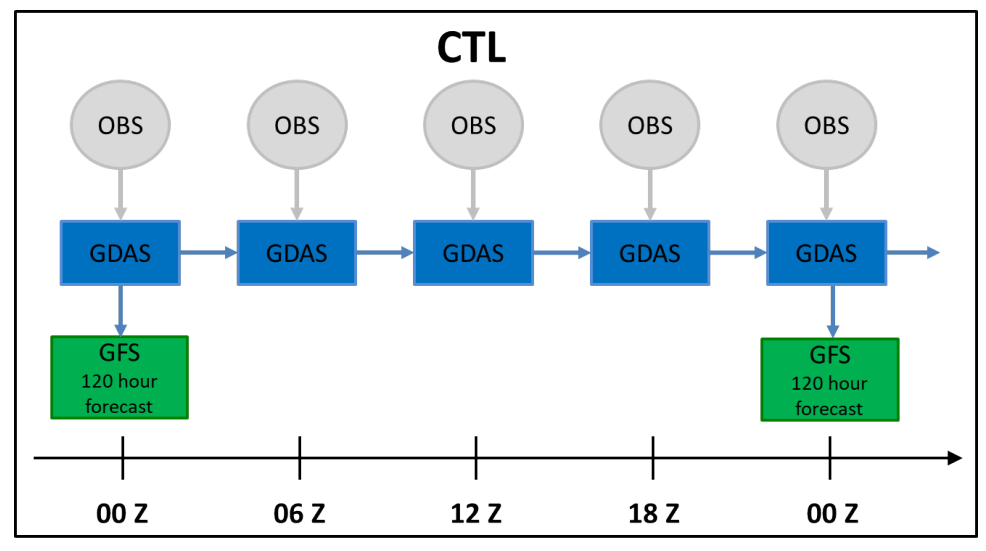

495

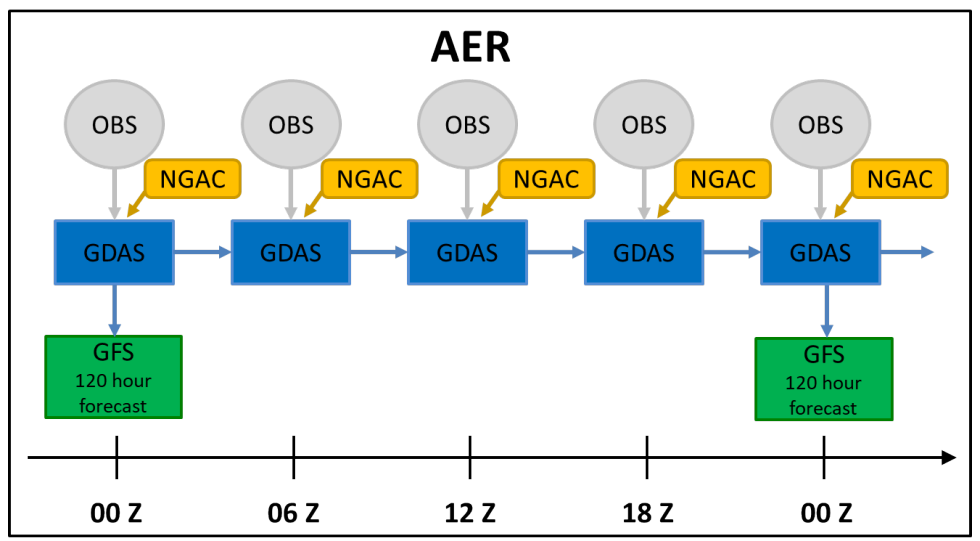

496

Figure 1. Schematic flow chart of the aerosol-blind (CTL) and aerosol-aware (AER) experiments for this study.

497 
https://doi.org/10.5194/acp-2021-129

Preprint. Discussion started: 21 July 2021

(c) Author(s) 2021. CC BY 4.0 License.

(a) Gert

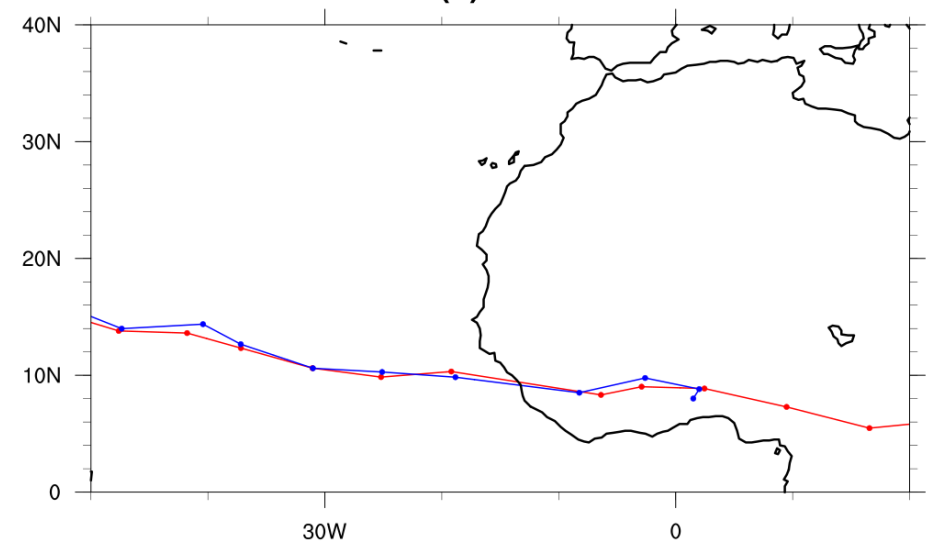

(b) Harvey

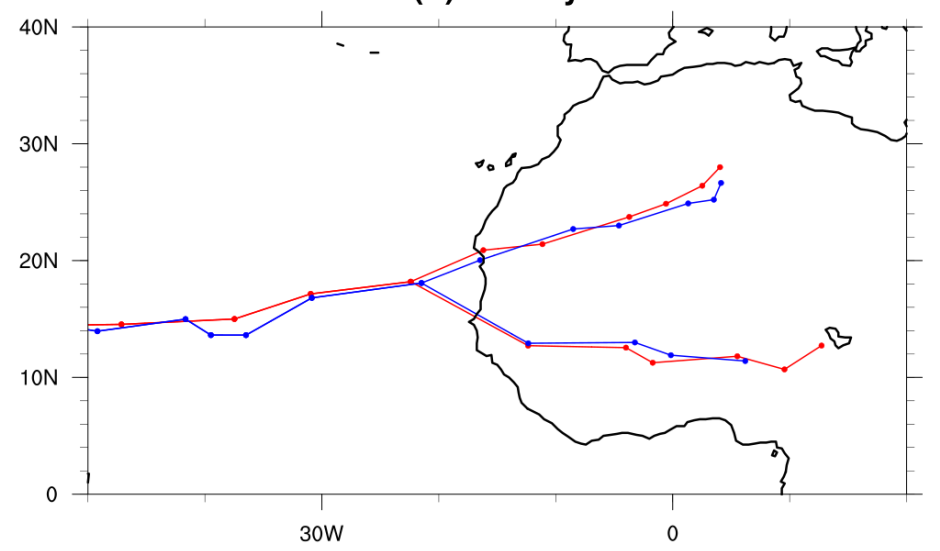

Figure 2. Daily locations of the AEWs corresponding to Gert and Harvey from the tracking algorithm in CTL (blue), AER (red). 
(a) U: [10W-10E]

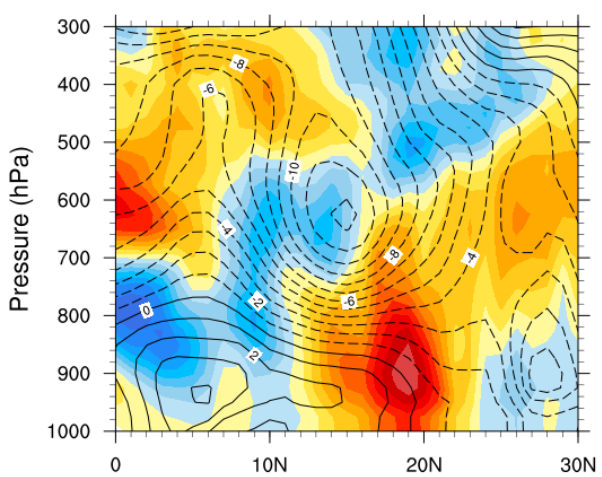

(b) $\mathrm{U}: 600 \mathrm{hPa}$

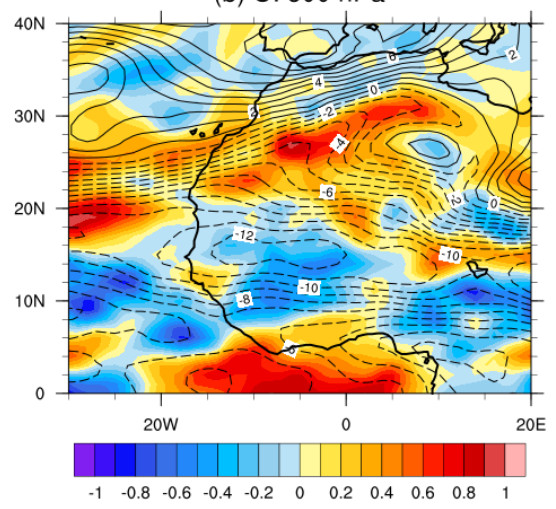

(c) $\mathrm{T}:[10 \mathrm{~W}-10 \mathrm{E}]$

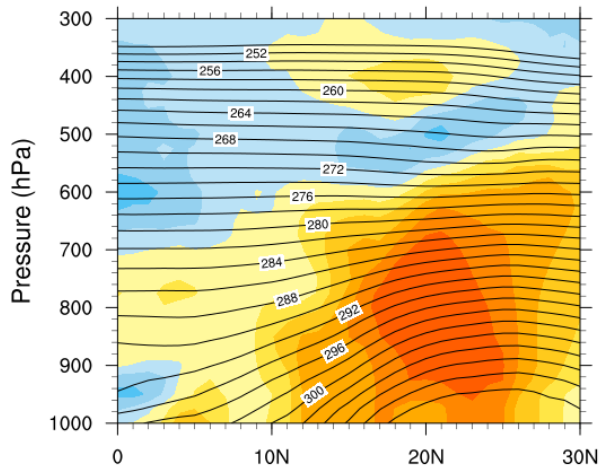

(d) $\mathrm{T}: 850 \mathrm{hPa}$

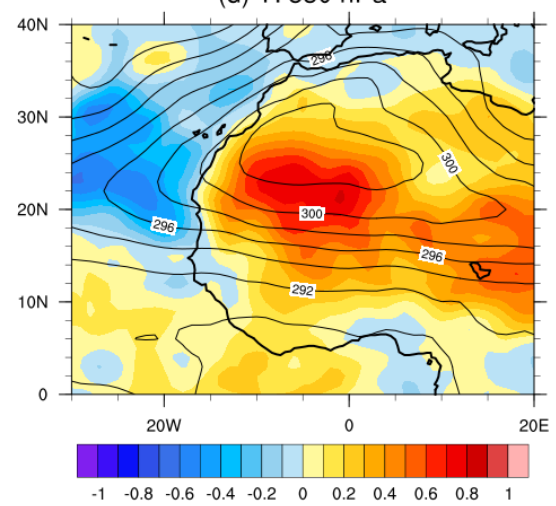

Figure 3. Horizontal and vertical plots of the CTL analysis (contours) and the AER - CTL analysis difference (colors) of the (a, 
https://doi.org/10.5194/acp-2021-129

Preprint. Discussion started: 21 July 2021

(c) Author(s) 2021. CC BY 4.0 License.

(a) VORT: [10W-10E]
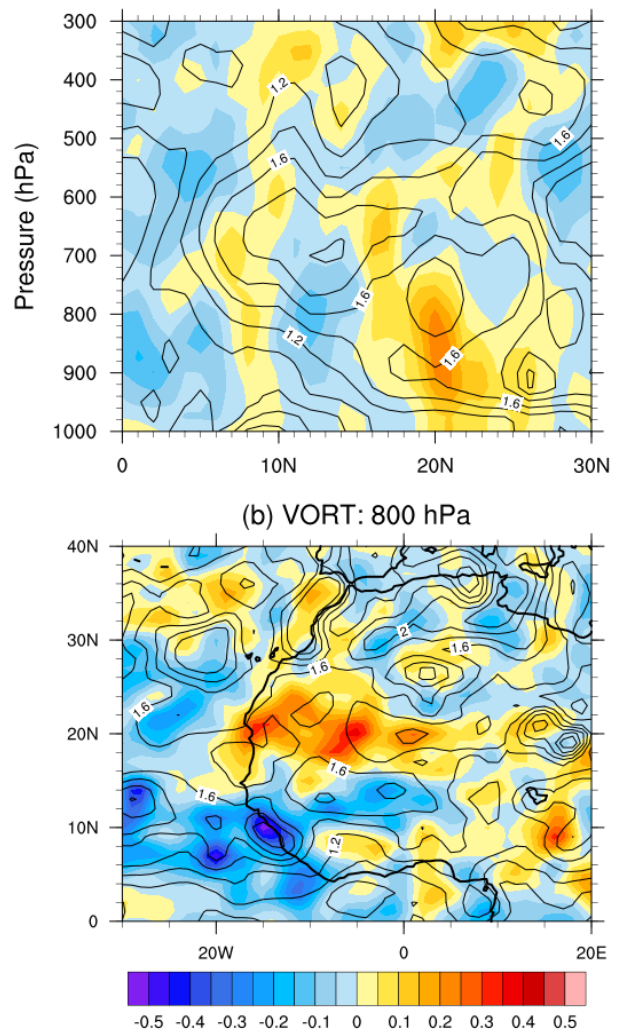

509 Figure 4. As in Fig. 3, but for the relative vorticity amplitude moduli, VORT $=(\zeta * \zeta)^{1 / 2}$, where $\zeta$ is the relative vorticity. 510 Contour/color units: $\times 10^{-5} \mathrm{~s}^{-1}$. 
(a) 08-01 00:00Z

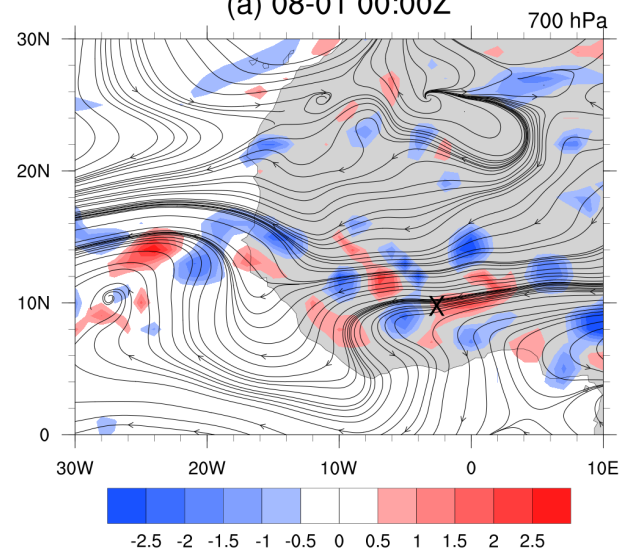

(c) $08-0300: 00 Z$

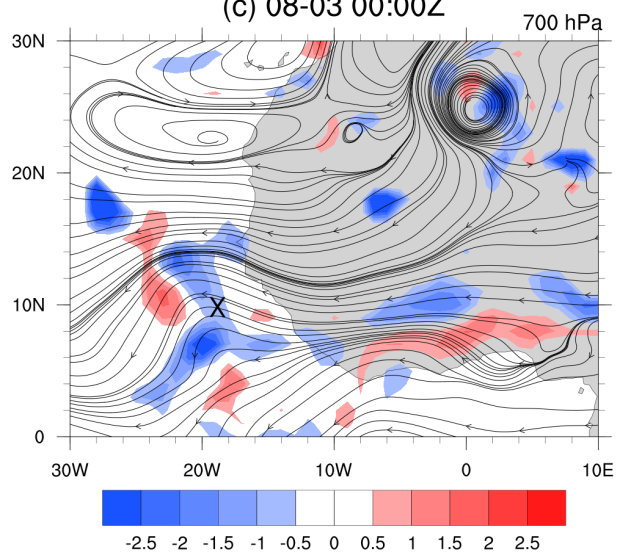

(b) 08-02 00:00Z

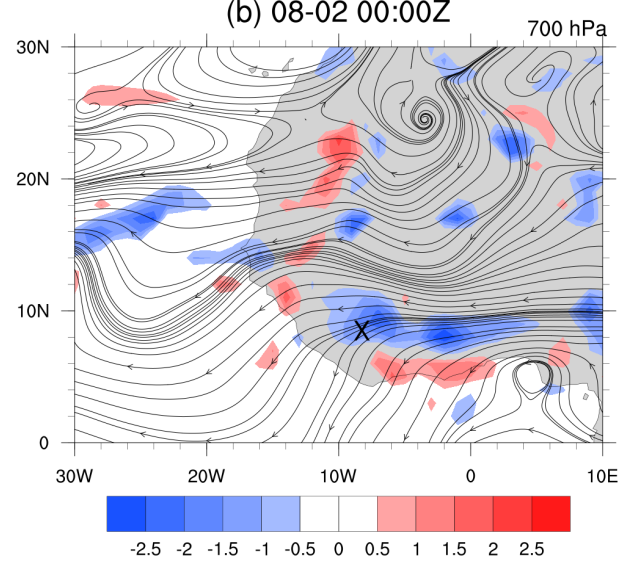

(d) 08-04 00:00Z

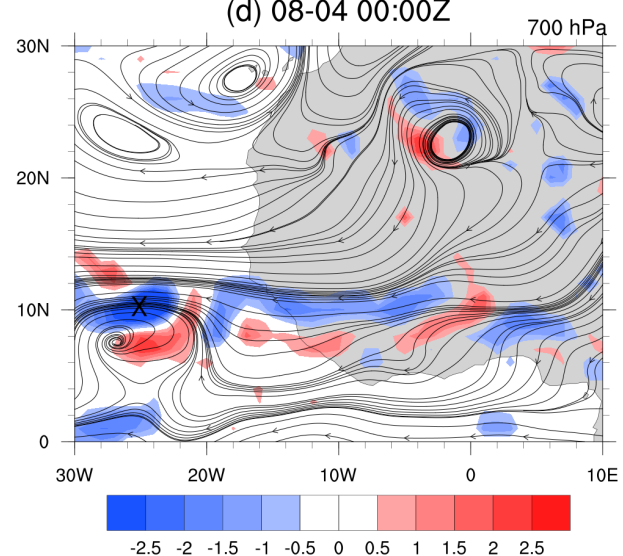

Figure 5. The evolution of the AEW associated with Gert. The panels show the $700 \mathrm{hPa}$ CTL streamlines (black) and the AER difference is more than $\pm 0.5 \times 10^{-5} \mathrm{~s}^{-1}$. 
https://doi.org/10.5194/acp-2021-129

Preprint. Discussion started: 21 July 2021

(c) Author(s) 2021. CC BY 4.0 License.

(c) (1)
Atmospheric

Chemistry

and Physics

Discussions

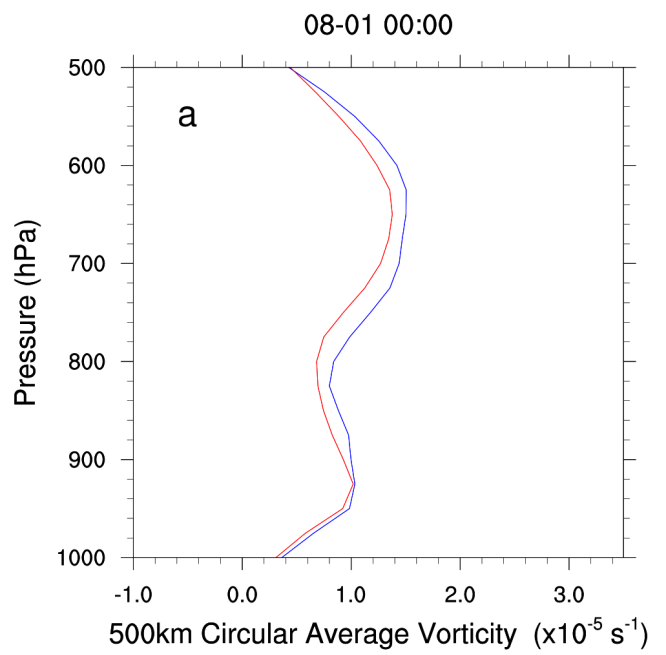

08-03 00:00

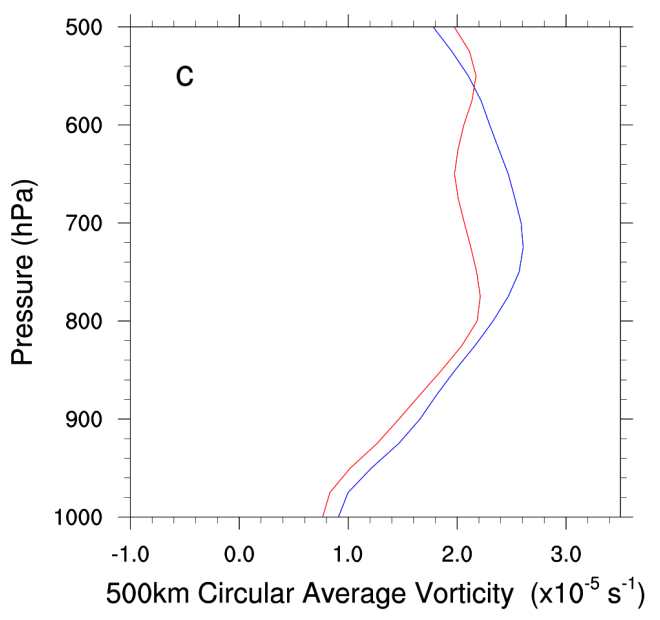

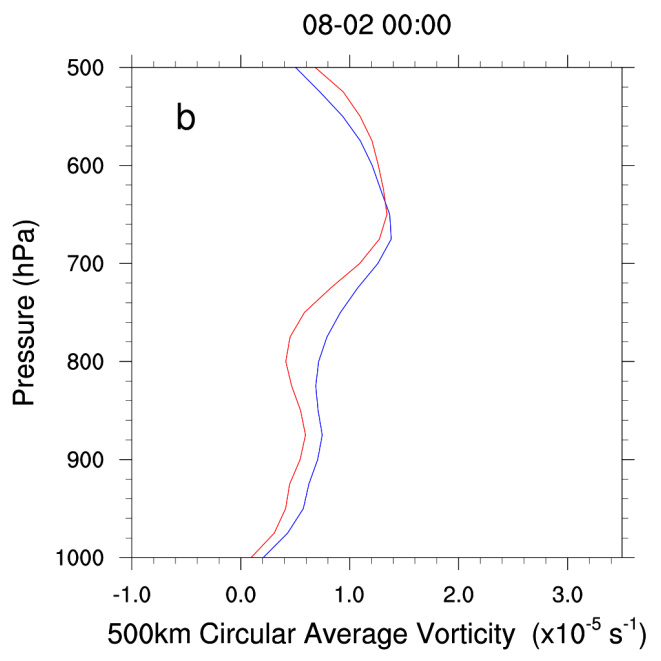

08-04 00:00

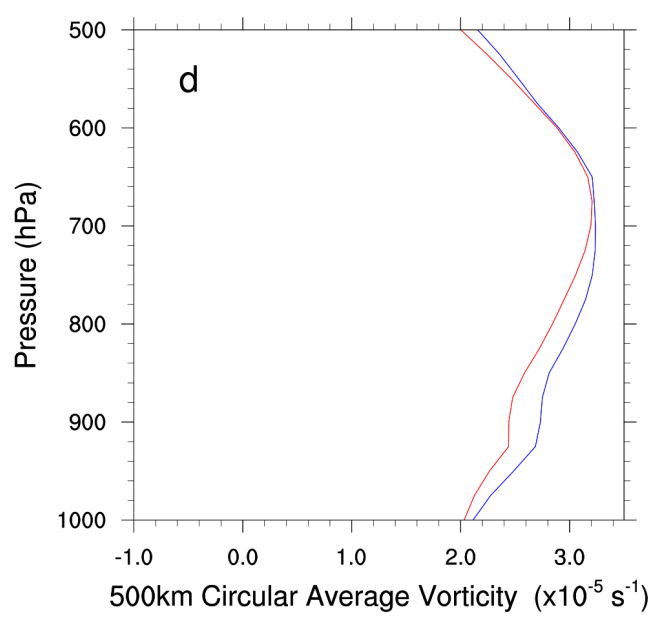

Figure 6. Vertical structures of the circular average vorticity (radius $500 \mathrm{~km}$ ) for the AEW associated with Gert for CTL (blue) and AER (red) during August $1^{\text {st }}-4^{\text {th }}$. The circular averages are taken at the X's shown in Fig. 5, which are determined from the wave tracking algorithm. 
https://doi.org/10.5194/acp-2021-129

Preprint. Discussion started: 21 July 2021

(c) Author(s) 2021. CC BY 4.0 License.
Atmospheric

Chemistry and Physics

Discussions (a) 08-09 00:00Z

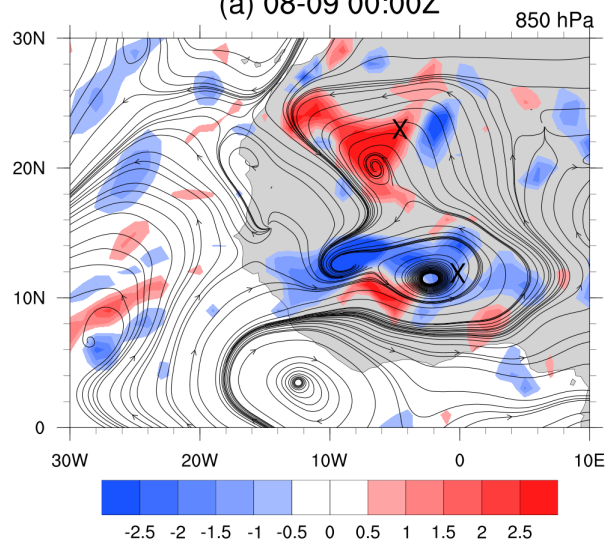

(c) $08-1100: 00 Z$

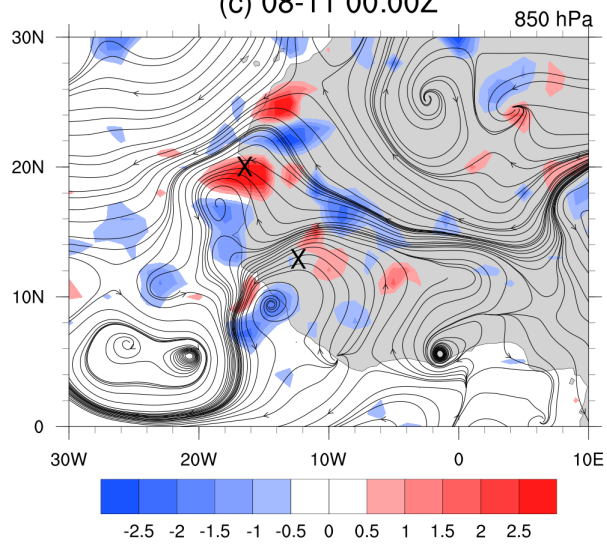

(b) $08-1000: 00 Z$

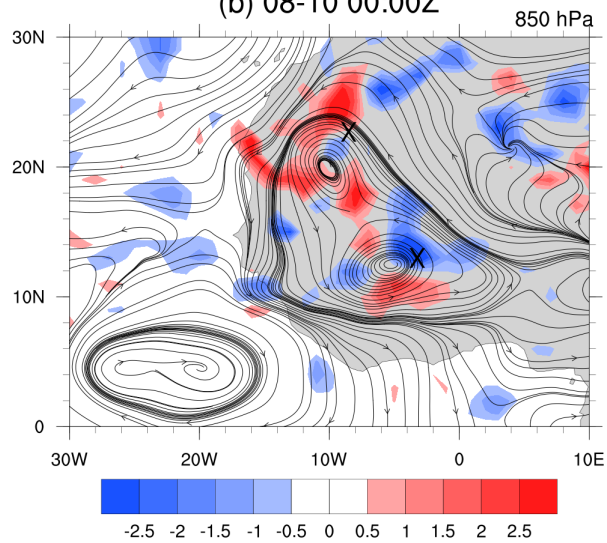

(d) 08-12 00:00Z

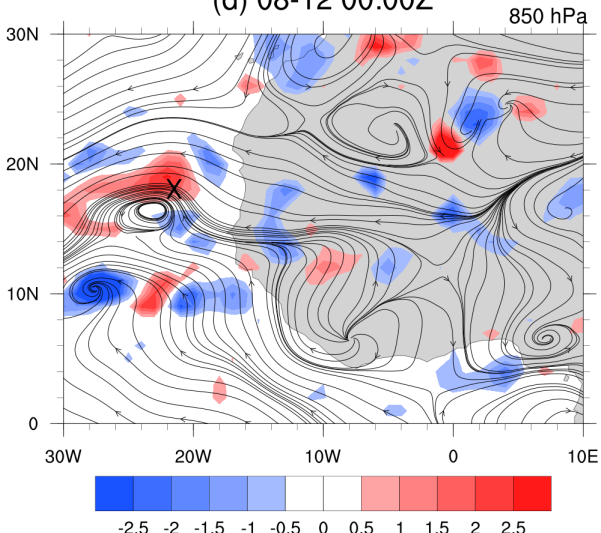

530

531 Figure 7. As in Fig. 5, but for the AEW associated with Harvey at $850 \mathrm{hPa}$. The date range is Aug $9^{\text {th }}-12^{\text {th }}$. 
https://doi.org/10.5194/acp-2021-129

Preprint. Discussion started: 21 July 2021

(c) Author(s) 2021. CC BY 4.0 License.

(c) (i)
Atmospheric

Chemistry

and Physics

Discussions
08-09 00:00

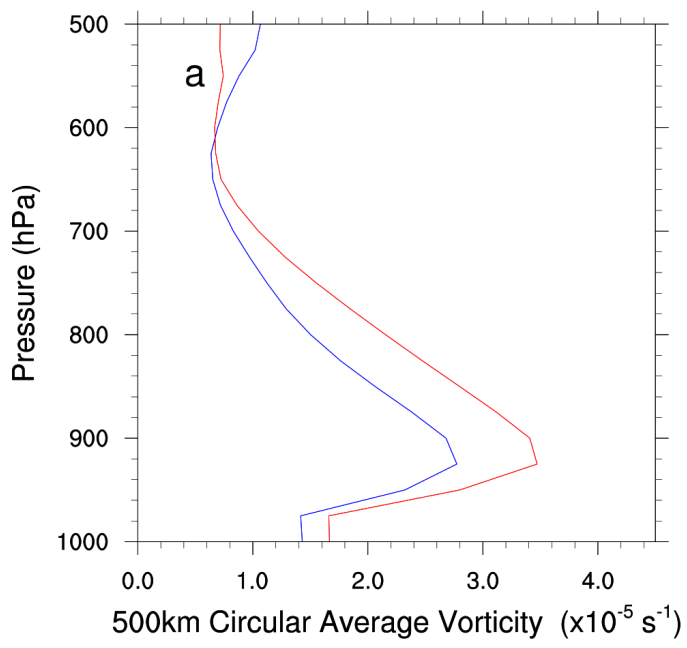

08-09 00:00

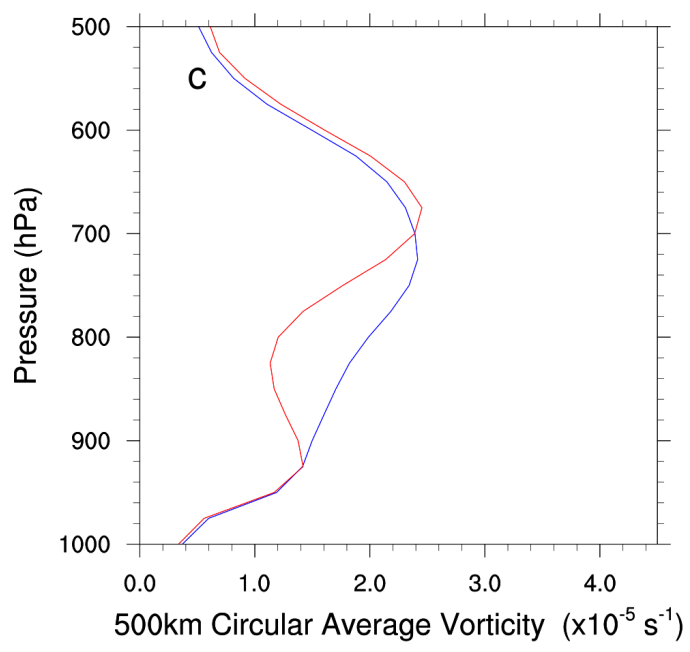

08-10 00:00

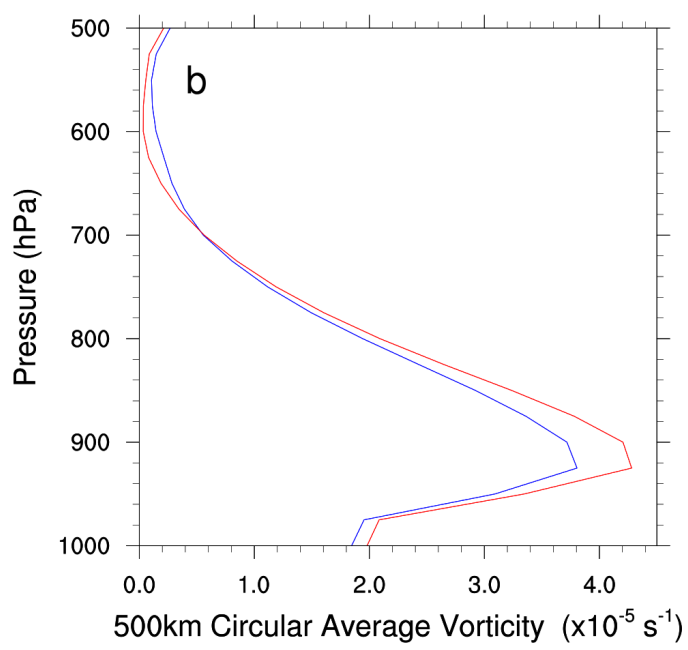

08-10 00:00

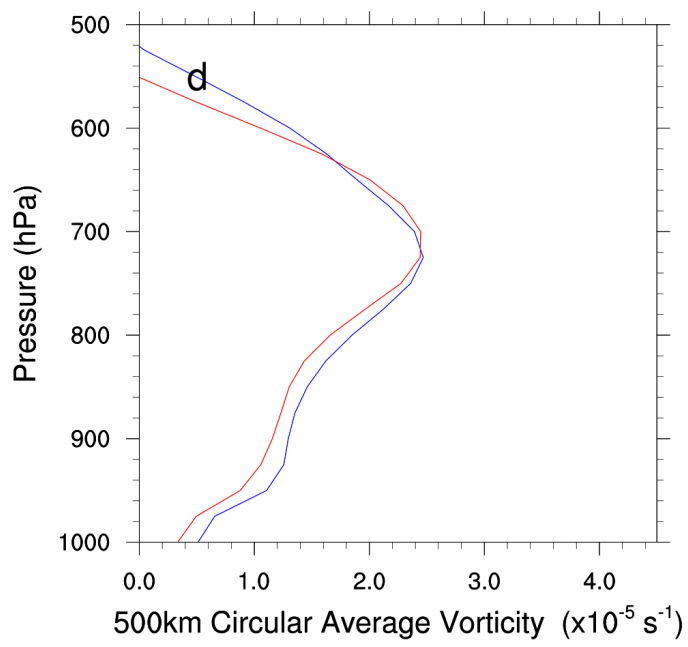

Figure 8. As in Fig. 6, but for the vertical structures of the northern (top) and southern (bottom) circulations of the AEW associated with Harvey during August $9^{\text {th }}-10^{\text {th }}$. 


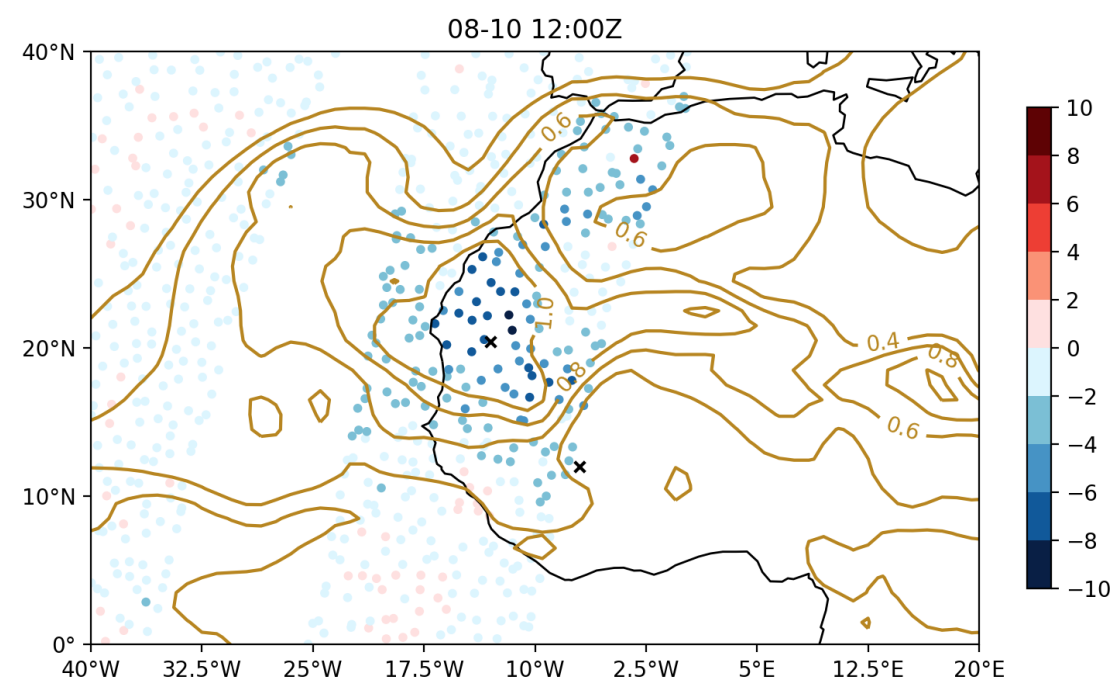

Figure 9. AER - CTL differences in simulated BT at $12.39 \mu \mathrm{m}$ from the IASI (circles) with the AOD on Aug 10 $0^{\text {th }} 12: 00 \mathrm{Z}$ (brown 542 contours). The X's mark the location of the wave centers for the AEW that developed Harvey (at $12^{\circ} \mathrm{N}, 17^{\circ} \mathrm{W}$ and $20.5^{\circ} \mathrm{N}, 13^{\circ} \mathrm{W}$ ). 


\begin{tabular}{|l|c|c|c|c|c|}
\hline \multicolumn{7}{|c|}{ Gert } \\
\hline Initialization & 1 day & 2 day & 3 day & 4 day & 5 day \\
\hline July $31^{\text {st }}$ & 0.13 & 0.21 & 0.19 & 0.38 & 0.03 \\
August $1^{\text {st }}$ & 0.17 & 0.27 & 0.25 & 0.10 & 0.08 \\
August $2^{\text {nd }}$ & 0.19 & 0.04 & 0.24 & 0.10 & 0.08 \\
$3^{\text {rd }}$ & 0.06 & 0.20 & 0.23 & 0.09 & 1.02 \\
\hline Augne
\end{tabular}

\begin{tabular}{|l|c|c|c|c|c|}
\hline Harvey \\
\hline Initialization & 1 day & 2 day & 3 day & 4 day & 5 day \\
\hline August $8^{\text {th }}$ & 0.23 & 0.05 & 0.23 & 0.32 & 0.27 \\
August $9^{\text {th }}$ & 0.08 & 0.07 & 0.06 & 0.33 & 0.32 \\
August $10^{\text {th }}$ & 0.35 & 0.32 & 0.17 & 0.31 & 0.49 \\
\cline { 2 - 3 } $11^{\text {th }}$ & 0.22 & 0.39 & 0.49 & 0.46 & 0.64 \\
\hline
\end{tabular}

Table 1. RMSE relative differences in the 1000 - $500 \mathrm{hPa}$ relative vorticity between the AER and CTL forecasts for the AEWs that developed Gert and Harvey. For each forecast day, the relative differences are calculated by taking (AER-CTL)/CTL of the RMSEs over the region following the AEW (see text for more details). The green values indicate AER improved the forecast, while red values indicate AER degraded the forecast; crossed-out values were not significant to the $99 \%$ confidence interval. The staircase border in each case separates times when the waves are onshore (upper left) and offshore (lower right). 